\title{
The Design and Implementation of Supply Chain Management System for Fast-Moving Consumer Goods Manufacturing Enterprise Based on SSH Linear Programming
}

\author{
Yu WANG ${ }^{1, a}$, Donglin WANG ${ }^{2}$ \\ 1,2Beijing Polytechnic, Beijing 100176, China \\ awangyu123@126.com
}

Keywords: Supply Chain Management; SSH Linear Programming; Vendor Managed Inventory

\begin{abstract}
This article in view of the international fast consumable manufacturing enterprises of supply chain management strategy, and in the supply chain procurement plan model, is proposed based on the improvement of VMI strategy, SSH linear programming model is established, and build the company's supply chain management system based on SSH linear programming. In this paper, through the study of vendor managed inventory (VMI) strategy, combined with international FMCG purchasing properties of production enterprises in the mainland China market, set up SSH linear programming as the core of supply chain management system. Core production by more accurate order data, to help companies reduce inventory, then achieves the effect of the supply chain inventory is decreasing, offers help to optimize the enterprise procurement plan.
\end{abstract}

\section{Introduction}

With the globalization of economy, great changes have taken place in world trade patterns. Since reform and opening up, China has gradually become the factory of the world, also in the position in world trade has become increasingly important. But relatively in developed countries, China itself is not master in science and technology advantages, also don't have money, procurement, sales and marketing advantage. This still does not have the too big change in a short time. How to reduce the cost of procurement, transportation, inventory, has always been a big problem in the enterprise. A growing number of local companies realize that profit in the low profit of trade competition, must set up an efficient supply chain system. Enterprise to in the purchase, transport, storage, sales link to better save costs and increase profits. For international enterprises, especially the fast consumable manufacturing enterprises, as a result of international division of labor, the core of enterprise products production, sales and other links are often distributed in different geographical areas [1-2]. Its fundamental purpose is in order to take advantage of different resources, reduce the enterprise cost, but also caused some of the production, transportation, storage, and even the increase of the cost of human resources.

Supply chain management arises at the historic moment, therefore, it is not a single corporation control the entire supply chain, but with customer demand as the major premise, through the continuous development of its core business, at the same time abandon non-core business, and work closely with other supply chain in enterprises, more effectively to achieve resource configuration is balanced, to create more added value for clients [3]. In under the guidance of this thought, each enterprise must from the global perspective to the whole supply chain, to establish a new relationship between supply and demand, to ensure that the whole supply chain system is low cost and highly efficient operation.

\section{The concept and basic thought of Vendor Managed Inventory}

Vendor Managed Inventory (VMI) is a cooperative strategy, users and suppliers to each other are the lowest cost to optimize the availability of the product, and the goal in a consensus within the framework of the vendor to manage inventory, the goal of this framework is modified to produce a kind of regular supervision and continuous improvement of the environment [4]. Therefore, VMI is 
suppliers instead of users (DSPS) inventory management. This article formulated the strategy, first of all, collect and organize the necessary information of upstream and downstream enterprises to the user, it responsible for the production planning and inventory management of the unified planning, provide solution for actual operation. This is actually the identity of the leader role in the supply chain, so start here called user unified core enterprise in this paper. All drive party strategy is the core enterprise. Second, in the supply chain inventory management, transportation management related to the supplier to confirm and complete the actual management operation. The specific process as shown in figure 1.

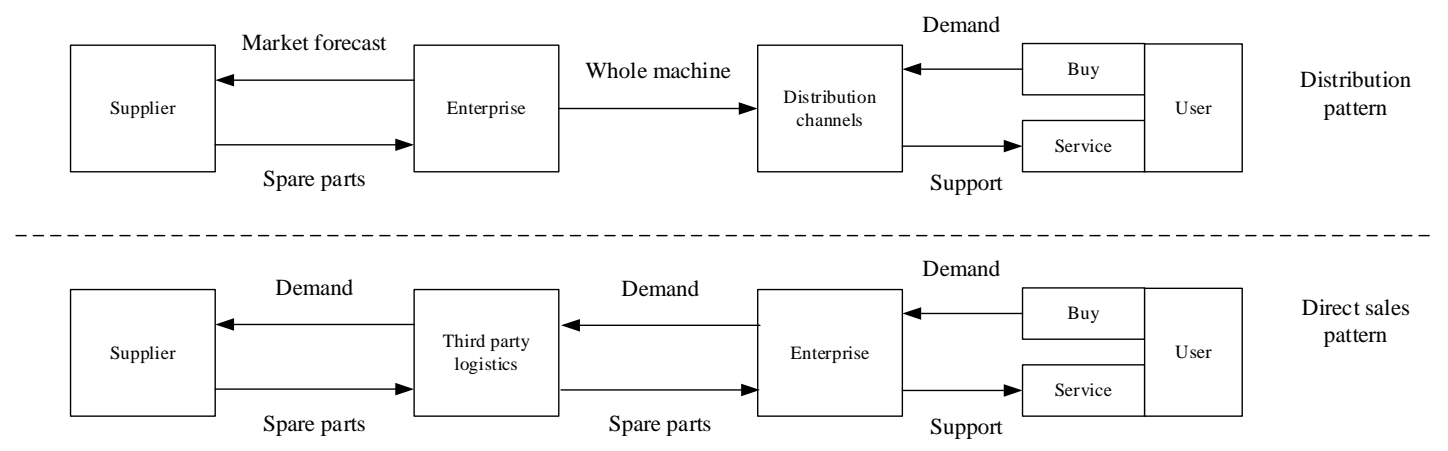

Figure 1. VMI Work Flow is improving

This paper realized the various warehouses and the necessary inventory is objective existence, could not be eliminated. You must formulate appropriate strategies to optimize the inventory. So, in this paper, considering both suppliers and users of inventory management, and they must be fused in a system planning. It increased the paper consider the details of the idea league to join the VMI inventory management. Not only should consider the inventory management, also want to consider the supplier's factory production factors and the user's factory production factors. Because the production of raw materials and products based on raw materials is decided in this paper, such as production and inventory management of the key factors. So, to strengthen cooperation between suppliers and users, not just to share the inventory information, but also the important information of production, to predict demand, facilitate the order plan. This is the most important thing. Due to the supplier and user cooperation was intensified, so duty problems are highlighted, which party is in the wake of a problem to solve, this is not only related to the normal operation of supply chain, and also is related to the vital interests of the organization.

\section{SSH linear programming model}

SSH linear programming is a multi-objective optimization model (MOLP).Can use the point estimation of multi-objective weighted sum method SSH are applied to solve the linear programming model (MOLP) point estimation is weighted sum method is used to solve the multi-objective SSH a method of linear programming (MOLP), by a group assignment is a weight, through which can the multi-objective linear programming problem into a normal SSH to solve the single objective of LP problem, and can get the multi-objective SSH non inferior solution of linear programming [5].

In the process of application, some problems in real environment formed the restricted factors of supply chain management strategy. The existence of these problems determines the SSH the basis of linear planning model is not suitable for direct application, must be to improve on relevant issues. Will propose below fast consumable manufacturing enterprises in the four types of problems in the process of supply chain management, and these problems of the constraint condition. To solve these problems, to SSH linear programming model to expand and improve. When you need to make order to the above situation forced to zero, need: there are two kinds of order production request order and shipped the order. Order is not necessarily a link between the two, can operate independently, so has the following constraints:

The production request order: 
vMfgReq $_{\text {prod,splrfac,splrwhs,t }}=0, \forall$ prod, splrfac, splrwhs, $\mathrm{t}$

Out of order request:

vShipReq $q_{\text {prod,splrwhs,site, }}=0, \forall$ prod, splrwhs, site, $\mathrm{t}$

SSH linear programming model to consider the product can be classified, classification after can be in this level product group request new constraints. Then bring into production quotas (MfgReqQuota) requests and out of the request quotas (ShipReqQuota) the two variables, it is concluded that the corresponding objective function is:

$\sum_{\substack{\text { splrfac } \\ \mathrm{t}}}^{\operatorname{grp}}$ vMfgReqQuotaOver grp,splrfac, $t+\underset{\substack{\text { splrwhs } \\ \mathrm{t}}}{\text { grp }}$ vShipReqQuotaOver ${ }_{\text {grp,splrwhs,t }}$

Minimum inventory strategy is a very important and is also a very dependent on procurement staff experience of a strategy. Given the objective function:

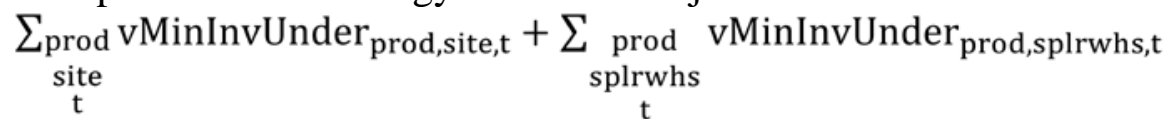

After a certain inventory level to ensure, can to some extent against fast great changes and fluctuations in demand. For example, in the prediction to many weeks and very large demand, and so can be one-time to supplier under sufficient quantity of orders, to produce first, slowly, because we know that sooner or later one day can be finished. But this one-time big orders can be dispersed into the planning cycle of each time period, which makes the curve of the procurement fluctuations decrease. On the other hand, the predicted after many weeks of very small demand, also can reduce the orders at a very early age, scatter the risk to the whole project cycle. The corresponding objective function is:

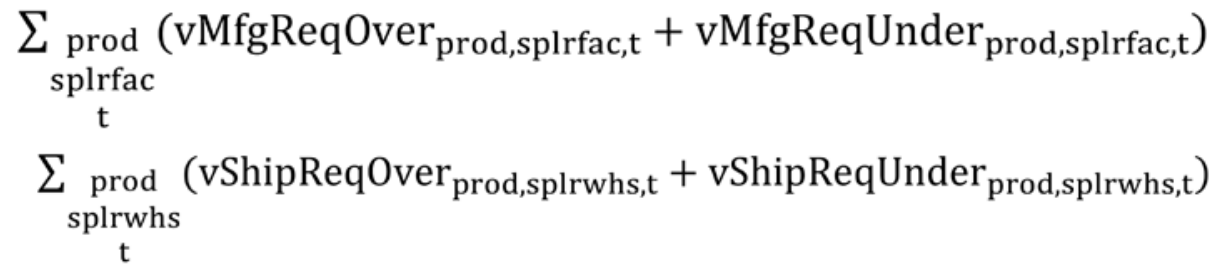

\section{Module design for supply chain management system}

In this paper, supply chain management system mainly completed the following main functions: (1) store from suppliers, core enterprise, distributors, and consumers' information, this information is for the purpose of computing needs of purchasing and inventory control plan, they should be done before entering the system filtering and necessary arrangement.(2) to access the information and make the necessary data extraction, organized into computing functional components of the input values in the system.(3) to implement all SSH in chapter 3 of the linear programming of constraints and objective function, and can find out the optimal solution.(4) will be the optimal solution of the data back to the database. Numerical solution (5) to organize and present the data into a purchase order, the user can view in some way, such as Microsoft Excel.

It can be regarded the system as a data processing factory, some by suppliers, core enterprise, customers get along the source data, through a complex process, into the last purchase order data you need. Figure 2 shows the main modules of the system. 


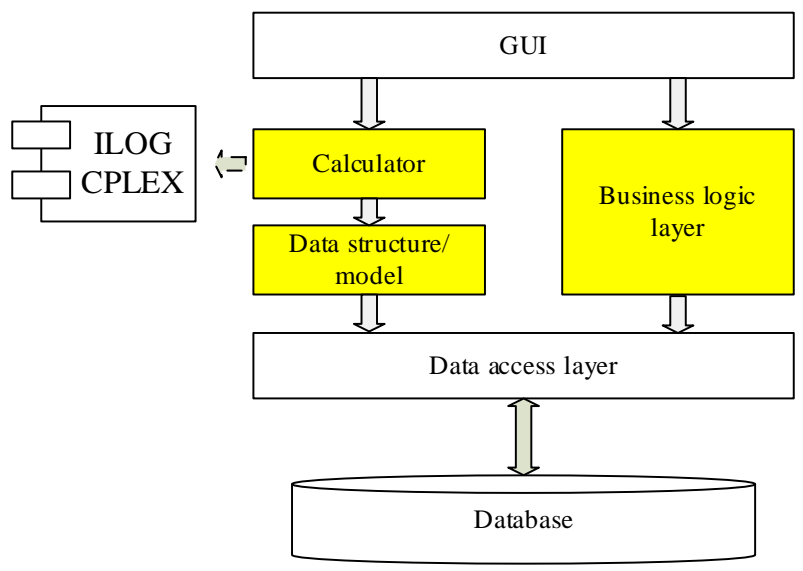

Figure 2. VMI Work Flow is improving

The graphical user interface module. It is for the unified system operation interface;

Calculator. It for the establishment of the model, the business logic of the organization, third party components ILOG SSH linear programming can call;

Data structure/model. It defined the SSH needed in linear programming model of a class definition, is the basis of the model. Business logic layer. It is for the computer expression of the various management and procurement strategy;

The data access layer. It is for the calculation module and database connection; The sixth is the database, provides the calculation module supports all the necessary data.

\section{Conclusion}

In order to ensure the production quality, part of the core material of the multinational operation of fast-moving consumer goods production and must rely on imports. The enterprise supply chain management puts forward the standard higher and stricter requirements of objective expectations. Therefore, to build a suitable for fast-moving consumer goods manufacturing enterprises in China international supply chain operation status quo of the supply chain management system, practical research significance in the current circumstances. At first, this article discussed the current commonly used international procurement management strategy, and on the basis of the commonly used methods of supply chain modeling based on vendor managed inventory, put forward to adapt to the international FMCG manufacturers of procurement in the Chinese market environment characteristics of procurement management strategy, completed the company supply chain management system based on SSH linear programming of the overall design. Based on supply chain management system based on SSH linear programming in practical engineering examples, the application on the reduction of multinational FMCG manufacturer's inventory has obvious effect.

\section{References}

[1] Johnson, G., M. Ortiz, and S. Leyendecker: Computer Methods in Applied Mechanics and Engineering 233 (2012): 49-67.

[2] Jabr, Rabih A., Ravindra Singh, and Bikash C. Pal: Power Systems, IEEE Transactions on 27.2 (2012): 1106-1115.

[3] Alshammari, Riyad, et al: Proceedings of the 11th Annual Conference Companion on Genetic and Evolutionary Computation Conference: Late Breaking Papers. ACM, 2009.

[4] Washio, Satoshi, et al: Optimization Methods and Software 28.4 (2013): 889-899.

[5] Sartor, Giorgio. "Optimal scheduling of smart home appliances using mixed-integer linear programming." (2012). 